\title{
ANEMIA ANCILOSTOMÓTICA: ESTUDO DA FISIOPATOLOGIA
}

Victório Maspes *

Michiru Tamigaki **

MASPES, V. \& TAMIGAKI, M. Anemia ancilostomótica: estudo da fisiopatologia. Rev. Saúde públ., S. Paulo, 15:611-22, 1981.

RESUMO: Foram estudados 17 casos de ancilostomose e determinados alguns parâmetros hematológicos como: dosagem de hemoglobina, do ferro sérico e da transferrina, contagem de hemácias, hematócrito, volume corpuscular médio (VCM) e hemoglobina corpuscular média (HCM). O estudo incluiu também a obtenção de alguns dados eritrocinéticos, como a determinação da velocidade de decaimento do ferro plasmático ( $T_{\text {a }}$ do ${ }^{5} \mathrm{Fe}$ ) e da incorporação do ferro à hemoglobina. O estudo radioisotópico permitiu ainda determinar o volume de sangue e a quantidade de hemoglobina perdida nas fezes, bem como o teor de ferro reabsorvido dessa hemoglobina. Estabeleceram também o grau de infecção através da contagem de ovos e de vermes nas fezes. Os doentes não apresentaram evidente alteração nutricional. A carência de ferro foi o fator comum a todos os casos que exibiram anemia, constituindo a base fisiopatológica da anemia ancilostomótica. O verme fixado à mucosa duodenal suga o sangue do hospedeiro e esta espoliação de sangue a longo prazo provoca a anemia. O volume de sangue perdido é geralmente proporcional ao grau de infecção, mas a quantidade de hemoglobina perdida mostrou ser independente do volume de sangue espoliado. A reabsorção de grande parte do farro da hemoglobina perdida na luz intestinal concorre para que a anemia se estabeleça mais tardiamente que em outras hemorragias como a vaginal. Os indivíduos anêmicos foram submetidos a transfusóes de sangue e com isso apresentaram melhora clínica e laboratorial, imediata mas temporária. A cura clínica foi estabelecida somente após tratamento adequado com vermífugos.

UNITERMos: Ancilostomose. Anemia. Hematologia.

\section{INTRODUÇÃO}

Dentre os primeiros trabalhos da literatura nacional que abordaram a anemia ancilostomótica, na década de 30 , sobressairam os de Osvaldo Cruz $3,4,5,3, \pi$. Este renomado pesquisador efetuou vários estudos em individuos ancilostomóticos, e determinou as condições sócio-econômicas e nutricionais. Correlacionou então a anemia ancilostomó- tica com o estado nutricional, de vez que eram individuos portadores de grande parasitose e de deficiente estado nutricional. Os métodos mais recentes de pesquisa, entretanto, trouxeram importantes contribuições para a elucidação da fisiopatologia da anemia ancilostomótica. Desse modo, esses novos conhecimentos vieram mostrar que a

* Do Serviço de Hematologia da Faculdade de Medicina da USP - Ar. Dr. Arnaldo, 455 - 01246 - São Paulo, SP - Brasil; do Laboratório de Hematologia da Unidade de Ensino e Pesquisa do Hospital Universitário. Caixa Postal 20876 - 01000 - São Paulo, SP - Brasil. *: Do Departamento de Medicina Preventiva da Faculdade de Medicina da USP - Av. Dr. Arnaldo, 455 - 01246 - São Paulo, SP - Brasil. 
MASPES, V. \& TAMIGAKI, M. Anemia ancilostomótica estudo da fisiopatologia. Rer. Saúde públ., S. Paulo, 15:611-22, 1981.

base fisiopatológica das anemias ancilostomótica e nutricional nāo são coincidentes.

A anemia nutricional apresenta mecanismo fisiopatológico diverso do da anemia ancilostomótica. $\mathrm{Na}$ ancilostomose, a anemia ciecorre essencialmente da espoliação de ferro, e confunde-se com qualquer outra anemia ferropênica. Esta anemia depende quase que exclusivamente da carência de ferro ocasionada pelas perdas sangüineas, - que não ocorre na anemia nutricional. Nesta última, a deficiência proteica pode constituir um dos aspectos fisiopatológicos da anemia. Por outro lado, a análise dos dados de eritrocinese mostra uma grande deficiência no transporte de oxigênio na anemia ancilostomótica, fato esse que não foi observado por Viteri na anemia do desnutrido proteico-energético ${ }^{1 ! .}$.

A dificuldade de encontrar-se um individuo com desnutrição proteico-energética pura em nosso meio ainda induz a muita confusão no estudo da fisiopatologia das duas entidades. Isto ocorre porque, em virtude das más condiçōes sócio-econômicas e de higiene, os desnutridos são também parasitados.

O presente trabalho visa contribuir para o estudo fisiopatológico do individuc porta. dor de anemia ancilostomótica. Assim, foram estudados pacientes portadores de infecção ancilostomótica, a maioria dos quais com severa anemia, mas senl desnutriçāo proteico-energética evidente. Os seguintes testes foram efetuados: dosagem de proteinas séricas, do ferro sérico, da transferrina e da hemoglobina no sangue; determinação cio humatócrito, contagem das hemácias, no sangue, cálculo do volume corpuscular médio (VCM) e da hemoglobina corpuscular média ( $\mathrm{HCM}$ ); determinação do volume de sangue perdido nas fezes, da quantidade de hemoglobina perdida nas fezes e do ferro reabsorvido dessa hemoglobina; determinaçāo da velocidade de decaimento do ferro plasmático ( $\mathrm{T}_{1 / 2}$ de ${ }^{5 \mathrm{Fe}}$ ) e da incorporação do ferro à hemoglobina. Estudou-se ainda o grau de infecção ancilostomótica atriavés da contagem de ovos e de vermes nas fezes. Todos os pacientes anêmicos foram transfundidos com $1.000 \mathrm{ml}$ a $2.000 \mathrm{ml}$ de sangue, de acordo com o grau de anemia.

\section{MATERIAL E MÉTODOS}

Foram estudados 17 doentes portacores de ancilostomiase, internados no Serviço do Hematologia do Hospital das Clinicas da Faculdade de Medicina da USP. Do total, 15 casos eram portadores de acentuado e os dois restantes, de leve grau de infecção. Houve casos de associação com outras parasitoses como ascariase, tricuriase e giardiase. Nenhum dos casos apresentou sitomas ou dados laboratoriais que sugerissem desnutrição proteico-energética.

A hemoglobina foi dosada pelo método da oxihemoglobina em meio alcalino

O hematócrito foi determinado pela técnica do microhematócrito.

A contagem de hemácias foi efetuada em câmara de Neubauer.

Oferro sérico e a transferrina total foram dosados pelo método de Ramsay modificado ${ }^{1 n}$.

As proteinas totais séricas foram dosadas pelo método de Gornall e col.11, e o fracionamento albumina-globulina foi efetuado pela precipitação das globulinas com sulfito de sódio a $21 \%$.

A velocidade de decaimento do ferro plasmático $\left(\mathrm{T}_{1 / 2}\right.$ de $\left.{ }^{34} \mathrm{Fe}\right)$ e a incorporaçăo do ferro à hemoglobina foram calculadas segundo técnica descrita por Maspes e col. ${ }^{14}$.

A determinação da quantidade de sangue perdido nas fezes obedeceu aos seguintes passos: as hemácias do doente foram marcadas com o radiocromato de sódio ( ${ }^{51} \mathrm{Cr}$ ), acrescentando-se o material radioativo, em doses adequadas, a $20 \mathrm{ml}$ de sangue venoso colhido com anticoagulante. Após $30 \mathrm{~min}$ de incubaçāo no meio ambiente, o sangue marcado era reinjetado. O radioferro (ja $\mathrm{Fe}$ ) foi também injetado, em doses adequadas, 7 dias antes do radiocromo pois, nesses doentes, que sāo carentes de ferro, esse 
MASPES, V. \& TAMIGAKI, M. Anemia ancilostomótica: estudo da fisiopatologia. Rei. Saúce públ., S. Paulo, 15:611-22, 1981.

período de tempo é suficiente para que haja incorporaçáo total do radıoferro. Esses dois procedimentos obedeceram à tecnica descrita por Maspes e col.1*. Dois dias após a marcaçāo com o radiocromo, inıciava-se a coleta de fezes, administrando-se ao doente $2 \mathrm{~g}$ de carmim, em cápsulas gelatinosas, e recomendando-se evacuar em recipiente adequado. Täo logo as fezes se tornassem avermelhadas, as mesmas eram colocadas em um pote de $2 \mathrm{~kg}$ de capacidade, previamente tarado. Esta colheita contınuava mesmo apos a normalização da cor das fezes. Quatro a seis dias após, à mesma hora da ingestão do carmim inicial, eram administradas ao doente outras $2 \mathrm{~g}$ de carmim, recomendando-se observar as fezes a partir desse momento. Para tal, o doente passava a evacuar normalmente em outro recipiente, e a colocar as fezes no pote até que o material se tornasse avermelhado, quando então deveria ser desprezado. $O$ pote era pesado a seguir, a fim de calcular o total das fezes nos 4 a 6 dias. Em seguida, o material do pote era homogeneizado, e uma amostra de cerca de $4 \mathrm{~g}$ era colocada em un tubo de contagem de radioatividade. Este tubo, que havia sido pesado anteriormente, era novamente pesado para obter-se o peso das fezes nele colocado. A seguir, o tubo era centrifugado, para equalizar a geometria das medidas de radiotividade. Durante esse periodo, o doente era mantido em regime alimentar pobre em resíduos. Além disso, $2 \mathrm{~g}$ de cáscara sagrada eram administradas todas as noites, com o intuito de evitar a constipação intestinal $e$ 0 endurecimento das fezes.

Amostras de sangue eram colhidas com anticoagulante $24 \mathrm{~h}$ antes do inicio da coleta de fezes, além de 2 a 3 amostras durante o período de coleta. Essas amostras eram lisadas com saponina, e de cada amostra um volume de $4 \mathrm{ml}$ era colocado em tubo de contagem. A medida da radioatividade dessas amostras tornou possivel a obtenção de uma curva, com a qual se calculou a atividade média do sangue no período de coleta das fezes.
As contagens de radioatividade das amostras eram efetuadas num mesmo dia, a fím de evitar o cálculo do decaimento físico.

Sabe-se que o cromo injetado e perdido nas fezes não é reabsorvido2,8. A quantidade de sangue perdida nas fezes por dia foi então calculada como se segue:

$$
\text { (1) } \mathrm{Sp}=\frac{\$ 1 \operatorname{Crf} \times P}{{ }_{51 \operatorname{Crs}}}
$$

\section{Sendo:}

$S p=$ sangue perdido nas fezes por dia em mililitros.

$\therefore \mathrm{Crf}=$ contagens por minuto do $\approx \mathrm{Cr}$ por grama de fezes.

$\therefore 1 \mathrm{Crs}=$ contagens por minuto do $5 \mathrm{Cr}$ por mililitro de sangue.

$P=$ Peso médio das fezes de $24 \mathrm{~h}$.

A quantidade total de hemoglobina perdida por dia pela via digestiva será:

$$
\text { (2) } \mathrm{Hp}=\frac{\mathrm{Hb} \times \mathrm{Sp}}{100}
$$

Sendo:

$$
\begin{aligned}
H p= & \text { hemoglobina total perdida pela via } \\
& \text { digestiva em gramas. } \\
H b= & \text { concentração de hemoglobina no } \\
& \text { sangue em gramas por dl. }
\end{aligned}
$$

O ferro total da hemoglobina perdida por dia pela via digestiva foi calculado através da seguinte fórmula:

(3) $\mathrm{Hfe}=\mathrm{Hp} \times 3,35$

\section{Sendo:}

Hfe = ferro total da hemoglobina perdida por dia.

$3,35=$ teor de ferro em $\mathrm{mg}$ por grama de hemoblobina.

A atividade do $59 \mathrm{Fe}$ por grama de hemoglobina no sangue foi calculada pela seguinte fórmula: 
MASPES, V. \& TAMIGAKI, M. Anemia ancilostomótica: estudo da fisiopatologia. Rev. Saúde públ., S. Paulo, 15:611-22, 1981 .

(4) $\mathrm{H}^{59} \mathrm{Fe}=\frac{\mathrm{S}^{59} \mathrm{Fe} \times 100}{\mathrm{Hb}}$

\section{Sendo:}

$\mathrm{H}^{59} \mathrm{Fe}=$ número de c.p.m. de ${ }^{59} \mathrm{Fe}$ por grama de hemoglobina.

$\mathrm{S}^{\bar{s} 9 \mathrm{Fe}}=$ número de c.p.m. por $\mathrm{ml}$ de sangue.

A atividade radioativa do ferro nas fezes de $24 \mathrm{~h}$ será:

(5) ${ }^{59} \mathrm{Fet}={ }^{59} \mathrm{Fef} \times \mathrm{P}$

\section{Sendo:}

${ }^{39} \mathrm{Fet}=$ número de c.p.m. de ${ }^{59} \mathrm{Fe}$ nas fezes de $24 \mathrm{~h}$.

${ }^{59} \mathrm{Fef}=$ número de c.p.m. de ${ }^{59} \mathrm{Fe}$ por grama de fezes.

Calcula-se a atividade radioativa do ferro da hemoglobina total perdida por dia nas fezes através da seguinte fórmula:

(6) $\mathrm{H}^{59} \mathrm{Fet}=\mathrm{H}^{59} \mathrm{Fe} \times \mathrm{Hp}$

\section{Sendo:}

$\mathrm{H}^{59} \mathrm{Fet}=$ número de c.p.m. do ${ }^{59} \mathrm{Fe}$ total da hemoglobina perdida por dia.

Portanto, a percentagem do ferro da hemoglobina perdida e eliminada com as fezes de $24 \mathrm{~h}$ é calculada como se segue:

(7) $\mathrm{Fe} \%=\frac{{ }^{59} \mathrm{Fet} \times 100}{\text { H }{ }^{59 \mathrm{Fet}}}$

Finalmente, o ferro da hemoglobina perdido e reabsorvido por dia será:

(8) Fer $=\frac{\mathrm{Hfe} \times(100-\mathrm{Fe} \%)}{100}$

\section{Sendo:}

Fer $=$ ferro hemoglobínico reabsorvido em $\mathrm{mg}$ por dia.

Portanto, a percentagem do ferro hemoglobinico reabsorvido por dia será:

(9) $\mathrm{Fer} \%=100-\mathrm{Fe} \%$
Para a contagem de ovos nas fezes de $24 \mathrm{~h}$ utilizou-se o método de Ferreira 9,10,13.

A contagem de vermes foi efetuada através do método de Amato Neto ${ }^{1}$, após dose adequada de tetracloroetileno.

\section{RESULTADOS}

A Tabela 1 mostra a idade dos 17 doentes estudados, que variou de 10 a 35 anos. Sete dos casos pertenciam ao sexo masculino e 10 casos ao sexo feminino. O peso corporal dos doentes variou de 25 a $59 \mathrm{~kg}$.

Seis casos referiram que os sintomas de anemia, como cansaço fácil, palpitações e fraqueza geral, se iniciaram havia menos de 1 ano, e seis casos, entre 1 a 5 anos, enquanto nos restantes cinco casos os sintomas surgiram mais de 5 anos antes da internação (Tabela 1).

Em dois casos (n०6 e no9) constatou-se a presença de esplenomegalia na ccasião do exame clínico, a qual foi mais tarde explicada pela presença de Schistosoma mansoni, cujos ovos foram identificados somente quando se procedeu à contagem de ovos nas fezes (Tabela 1).

A Tabela 2 mostra as taxas de hemoglobina e de hematócrito, determinadas no primeiro atendimento aos 17 doentes. Os resultados variaram de $1,8 \mathrm{~g} / \mathrm{dl}$ a $13,0 \mathrm{~g} / \mathrm{dl}$ de hemoglobina e de $7 \%$ a $41 \%$ de hematócrito. Na mesma Tabela, observa-se que a variação do no de eritrócitos, em 15 casos, foi de $0,8 \times 10^{6 / \mathrm{mm}^{3}}$ a $4,2 \times 10^{6 /} / \mathrm{mm}^{3}$, enquanto a hemoglobina corpuscular média variou de $16 \mathrm{pg}$ a $30 \mathrm{pg}$, e o volume corpuscular médio, de $60 \mathrm{u}^{3} a 97 \mathfrak{u}^{3}$.

A Tabela 3 mostra que a taxa de hemoglobina dos 17 casos, após internação, variou de $2,3 \mathrm{~g} / \mathrm{dl}$ a $13,0 \mathrm{~g} / \mathrm{dl}$.

Quanto às proteinas totais, houve uma variação de $5,8 \mathrm{~g} / \mathrm{dl}$ a $9,0 \mathrm{~g} / \mathrm{dl}$, como consta na Tabela 3 , enquanto a albumina sérica 
MASPES, V. \& TAMIGAKI, M. Anemia ancilostomótica: estudo da fisiopatologia. Rev. Saúde públ., S. Paulo, $15: 611-22,1981$.

T A B E L A 1

Pacientes portadores de ancilostomose, segundo sexo, idade, peso corporal e início dos sintomas.

\begin{tabular}{|c|c|c|c|c|}
\hline Caso & Sexo & $\begin{array}{l}\text { Idade } \\
\text { (anos) }\end{array}$ & $\begin{array}{c}\text { Peso } \\
\text { corporal (kg) }\end{array}$ & $\begin{array}{l}\text { Início dos } \\
\text { sintomas }\end{array}$ \\
\hline 1 & masc. & 10 & 28 & t2 \\
\hline 2 & masc. & 11 & 25 & $\mathrm{t} 2$ \\
\hline 3 & fem. & 19 & 42 & $\mathrm{t} 1$ \\
\hline 4 & fem. & 30 & 59 & t1 \\
\hline 5 & $f \in m$. & 31 & 42 & $\mathrm{t} 3$ \\
\hline $6 *$ & masc. & 53 & 51 & $\mathrm{t} 3$ \\
\hline 7 & masc. & 22 & 55 & $\mathrm{t} 1$ \\
\hline 8 & fem. & 18 & 44 & $\mathrm{t} 1$ \\
\hline $9 *$ & masc. & 20 & 39 & $\mathrm{t} 3$ \\
\hline 10 & masc. & 15 & 26 & $\mathrm{t} 2$ \\
\hline 11 & fem. & 23 & 42 & $\mathrm{t} 3$ \\
\hline 12 & fem. & 21 & 45 & $\mathrm{t} 2$ \\
\hline 13 & masc. & 18 & 48 & $\mathrm{t} 1$ \\
\hline 14 & fem. & 26 & 40 & $\mathrm{t} 2$ \\
\hline 15 & fem. & 25 & 39 & t3 \\
\hline 16 & fem. & 40 & 49 & t2 \\
\hline 17 & fem. & 26 & 43 & t1 \\
\hline
\end{tabular}

* Portador de esquistossomose mansônica, forma hepatoesplênica.

t1 - menos de um ano

t2 - de 1 a cinco anos

t3 - mais de 5 anos.

T A B E L A 2

Pacientes portadores de ancilostomose, segundo hemoglobina, hematócrito, eritrócitos, volume corpuscular médio (VCM) e hemoglobina corpuscular média (HCM) *

\begin{tabular}{|c|c|c|c|c|c|}
\hline Caso & $\begin{array}{l}\text { Hemoglobina } \\
(\mathrm{g} / \mathrm{dl})\end{array}$ & $\begin{array}{l}\text { Hematócrito } \\
(\%)\end{array}$ & $\begin{array}{l}\text { Eritrócitos } \\
(\mathrm{x} 106 \mathrm{~mm} 3)\end{array}$ & $\begin{array}{l}\text { VCM } \\
\left(\begin{array}{ll}\mathrm{u} 3\end{array}\right)\end{array}$ & $\begin{array}{c}\mathrm{HCM} \\
(\mathrm{pg})\end{array}$ \\
\hline 1 & 3,5 & 15 & 1.7 & 88 & 20 \\
\hline 2 & 8,2 & 32 & 3.5 & 91 & 23 \\
\hline 3 & 6,6 & 22 & 2,3 & 95 & 28 \\
\hline 4 & 6.0 & 19 & $\ldots$ & $\ldots$ & $\ldots$ \\
\hline 5 & 2,1 & 7 & 0.8 & 87 & 26 \\
\hline 6 & 4,1 & 13 & 1,4 & 92 & 29 \\
\hline 7 & 11,8 & 39 & 4,0 & 97 & 29 \\
\hline 8 & 5,4 & 22 & 2,4 & 91 & 22 \\
\hline 9 & 1,8 & 7 & 0.9 & 77 & 20 \\
\hline 10 & 7,5 & 29 & 3.0 & 96 & 25 \\
\hline 11. & 5,2 & 21 & 2.3 & 91 & 22 \\
\hline 12 & 2,8 & 14 & - & $\ldots$ & $\ldots$ \\
\hline 13 & 6.3 & 24 & 4,0 & 60 & 16 \\
\hline 14 & 6.4 & 24 & 3,1 & 77 & 20 \\
\hline 15 & 6,4 & 24 & 3,7 & 64 & 17 \\
\hline 16 & 4,2 & 19 & 2,6 & 73 & 16 \\
\hline 17 & 13.0 & 41 & 4.2 & 97 & 30 \\
\hline
\end{tabular}

* Dados obtidos no primeiro atendimento ambulatorial ao doente. 
MASPES, V. \& TAMIGAKI, M. Anemia ancilostomótica: estudo da fisiopatologia. Rev. Saúde públ,, S. Paulo, 15:611-22, 1981.

mostrou-se variável de $2,6 \mathrm{~g} / \mathrm{dl}$ a $6,3 \mathrm{~g} / \mathrm{dl}$ $\mathrm{e}$ as globulinas séricas, de $1,5 \mathrm{~g} / \mathrm{dl}$ a 3,7 $\mathrm{g} / \mathrm{dl}$, nos 17 casos.

O ferro sérico, nos 17 casos, apresentou uma variação de $18 \mathrm{ug} / \mathrm{dl}$ a $155 \mathrm{ug} / \mathrm{dl}$, enquanto a transferrina total mostrou uma variação de $272 \mathrm{ug} / \mathrm{dl}$ a $499 \mathrm{ug} / \mathrm{dl}$, em 14 casos (Tabela 3).

Os valores do $T_{1 / 2}$ de 5 : $\mathrm{Fe}$ e da incorporação do ferro à hemoglobina foram determinados em 8 casos. A variação do primeiro foi de 13 a $41 \mathrm{~min}$, e a da incorporação do ferro foi de 80 a $100 \%$ (Tabela 4).

Pode-se observar ainda na Tabela 4 que a hemorragia intestinal nos 17 casos mostrou-se variável de $0,2 \mathrm{ml}$ a $199,4 \mathrm{ml}$ de sangue por dia, e a perda hemoglobínica intestinal variou de $0,03 \mathrm{~g} / \mathrm{dia}$ a $5,4 \mathrm{~g} / \mathrm{dia}$. $O$ ferro total perdido na hemorragia intestinal mostrou uma variação de $0,1 \mathrm{mg} / \mathrm{dia}$ a $18,1 \mathrm{mg} /$ dia. Quanto ao ferro reabsorvido da hemorragia, determinado nesses 8 casos, mostrou uma variação de $1,6 \mathrm{mg} /$ dia a 11,9 $\mathrm{mg} / \mathrm{dia}$ e, percentualmente, de 38 a $68 \%$. Calculou-se também o ferro efetivamente perdido nas fezes em 8 casos e que variou de $2,1 \mathrm{mg} /$ dia a $6,2 \mathrm{mg} /$ dia.

O número de ovos nas fezes, no período de $24 \mathrm{~h}$, determinado em 14 casos, mostrou uma variação de $75 \times 10^{3}$ a $12.200 \times 10^{3}$, enquanto o número de ovos por grama de fezes variou de $0,6 \times 10^{3}$ a $120 \times 10^{3}$ (Tabela 5). O número de vermes variou de 15 a 2.655, em 11 casos (Tabela 5).

A Tabela 6 mostra que o volume de sangue transfundido em 15 casos variou de $1.000 \mathrm{ml}$ a $2.000 \mathrm{ml}$.

\section{DISCUSSAO}

Uma das condiçōes que mais colaboram para confundir a anemia ancilostomótica com a do desnutrido protéico-energético é a grande semelhança quanto ao aspecto clínico. O desenvolvimento físico e intelectual não é normal, ou seja, há atraso no crescimento pondo-estatural e na escolaridade.

T A B E L A 3

Pacientes portadores de ancilostomose, seg:ndo hemoglobina, proteinas totais e fraçôes e ferro e transferrina séricos *.

\begin{tabular}{|c|c|c|c|c|c|c|}
\hline Caso & $\begin{array}{l}\text { Hemoglobina } \\
\qquad(\mathrm{g} / \mathrm{dl})\end{array}$ & $\begin{array}{l}\text { Proteinas } \\
\text { totais } \\
(\mathrm{g} / \mathrm{dl})\end{array}$ & $\begin{array}{l}\text { Albumina } \\
(\mathrm{g} / \mathrm{dl})\end{array}$ & $\begin{array}{l}\text { Globtlinas } \\
\quad(g / d l) \\
=\end{array}$ & $\begin{array}{c}\text { Ferro } \\
\text { (ug/dl) }\end{array}$ & $\begin{array}{l}\text { Transferring } \\
\text { (ug/dl) }\end{array}$ \\
\hline 1 & 6,4 & 6,7 & 3,9 & 2,8 & 21 & 360 \\
\hline 2 & 8,8 & 5,9 & 3,5 & 2,4 & 38 & 359 \\
\hline 3 & 6,2 & 6,5 & 3.8 & 2,7 & 39 & $\ldots$ \\
\hline 4 & 4,6 & 6.0 & 3,5 & 2,5 & 18 & $\ldots$ \\
\hline 5 & 2,3 & 5,8 & 2,6 & 3,2 & 53 & 402 \\
\hline 6 & 4,2 & 8,1 & 4,4 & 3.7 & 37 & 455 \\
\hline 7 & 11,8 & 9,0 & 6,3 & 2.7 & 78 & 473 \\
\hline 8 & 9.8 & 7,9 & 4,6 & 3,3 & 32 & 312 \\
\hline 9 & 4,2 & 6,5 & 3,5 & 3,0 & 22 & 432 \\
\hline 10 & 5,9 & 7,2 & 4.9 & 2.3 & 29 & 311 \\
\hline 11 & 5,2 & 7.0 & 5,5 & 1,5 & 45 & 272 \\
\hline 12 & 2,8 & 6,3 & 3,9 & 2.4 & 19 & $\ldots$ \\
\hline 13 & 7,3 & 7.0 & 5,0 & 2,0 & 27 & 499 \\
\hline 14 & 6,9 & 6.9 & 4.4 & 2,5 & 50 & 423 \\
\hline 15 & 6,4 & 7,1 & 4,8 & 2.3 & 18 & 442 \\
\hline 16 & 5,3 & 6.3 & 3,9 & 2.4 & 49 & 474 \\
\hline 17 & 13,0 & 8,7 & 5.1 & 3.6 & 155 & 328 \\
\hline
\end{tabular}

* Dados obtidos logo após ì internação do doente. 


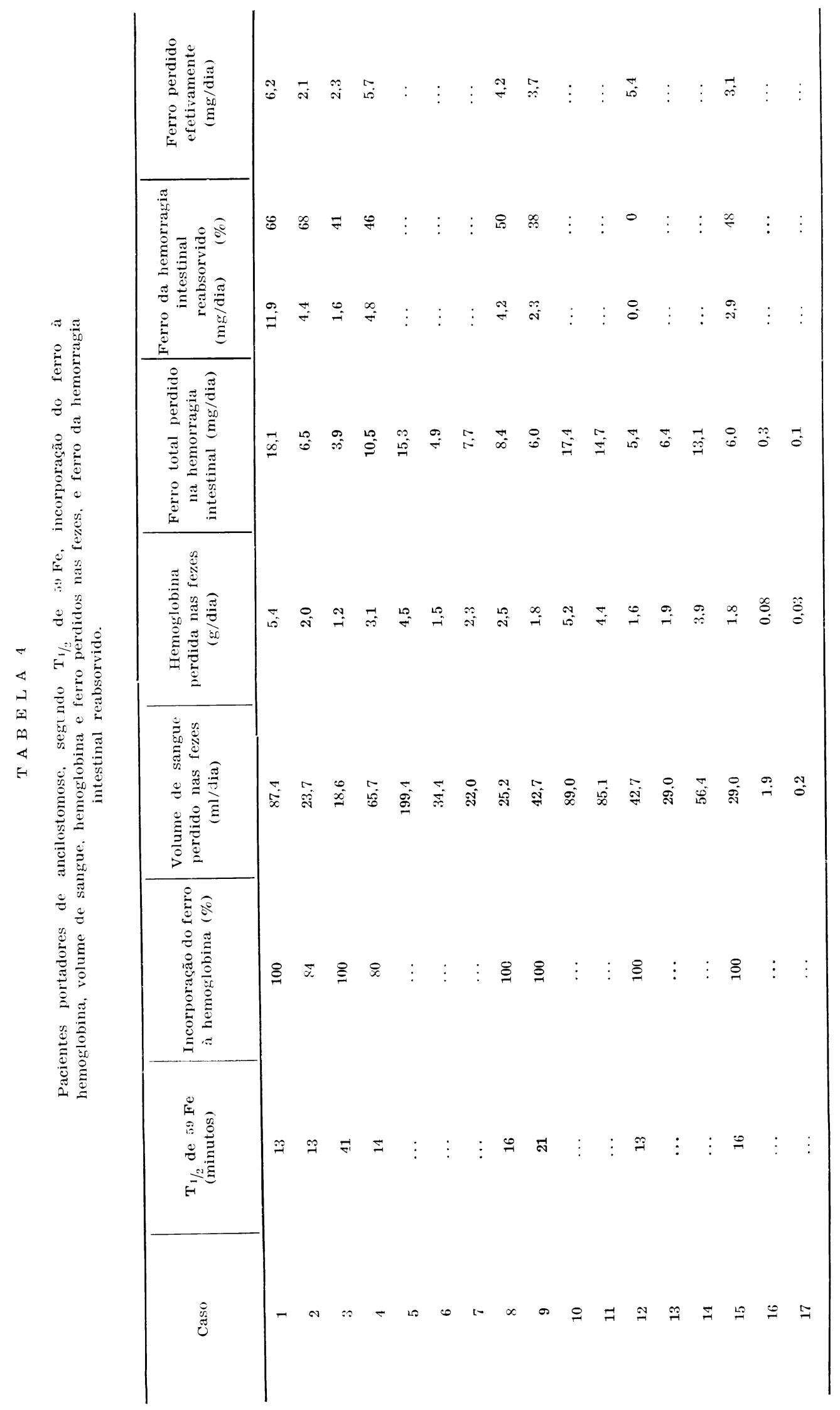


MASPES, V. \& TAMIGAKI, M. Anemia ancilostomótica: estudo da fisiopatologia. Rev. Saúde públ., S. Paulo, 15:611-22, 1981 .

\section{T A B E L A 5}

Pacientes portadores de ancilostomose, segundo contagem de ovos de ancilostomídeos e número de vermes.

\begin{tabular}{|c|c|c|c|}
\hline Caso & $\begin{array}{l}\text { Númer } \\
\text { nas fezes de } \\
24 \text { horas }(\text { x10 3) }\end{array}$ & $\begin{array}{l}\text { ovos } \\
\text { por grama de } \\
\text { fezes }(\text { x10 3) }\end{array}$ & $\begin{array}{l}\text { Número de } \\
\text { vermes * }\end{array}$ \\
\hline 1 & 4.960 & 21,3 & 605 \\
\hline 2 & 3.640 & 28,0 & 613 \\
\hline 3 & 513 & 3,4 & \\
\hline 4 & 10.800 & 120,0 & $\ldots$ \\
\hline 5 & 10.400 & 104,0 & 2.655 \\
\hline 6 & $\ldots$ & $\ldots$ & 367 \\
\hline 7 & 6.200 & 18,2 & 302 \\
\hline 8 & 3.800 & 15,6 & 879 \\
\hline 9 & 7.600 & 116,8 & 693 \\
\hline 10 & 4.200 & 43,5 & $\ldots$ \\
\hline 11 & 12.200 & 47,8 & 355 \\
\hline 12 & 7.500 & 67,0 & 893 \\
\hline 13 & 2.950 & 28,3 & $\ldots$ \\
\hline 14 & $\ldots$ & & \\
\hline 15 & . & $\ldots$ & . \\
\hline 16 & 78 & 0,9 & 17 \\
\hline 17 & 75 & 0,6 & 15 \\
\hline
\end{tabular}

* Contados nas fezes após administração de tetracloroetileno.

T A B E L A 6

Pacientes portadores de ancilostomose, segundo volume de sangue transfundido, dosagem de hemoglobina antes e após transfusões de sangue.

\begin{tabular}{|c|c|c|c|}
\hline \multirow{2}{*}{ Caso * } & \multirow{2}{*}{$\begin{array}{l}\text { Volume de sangue } \\
\text { transfundido }(\mathrm{ml})\end{array}$} & \multicolumn{2}{|c|}{ Hemoglobina (g/dl) } \\
\hline & & A & D \\
\hline 1 & 1.200 & 6,4 & 10,2 \\
\hline 2 & 1.200 & 8,8 & 11,9 \\
\hline 3 & 1.500 & 6,2 & 12,4 \\
\hline 4 & 1.500 & 4,6 & 10,9 \\
\hline $\mathbf{5}$ & 2.000 & 2,3 & 8,7 \\
\hline 6 & 1.500 & 4,2 & 7,3 \\
\hline 8 & 2.000 & 9,8 & 11,1 \\
\hline 9 & 1.500 & 4,2 & 10,5 \\
\hline 10 & 1.500 & 5,9 & 9,9 \\
\hline 11 & 1.000 & 5,2 & 9,9 \\
\hline 12 & 2.000 & 2,8 & 11,0 \\
\hline 13 & 2.000 & 7,3 & 12,0 \\
\hline 14 & 2.000 & 6,9 & 12,4 \\
\hline 15 & 1.500 & 6,4 & 10,8 \\
\hline 16 & 2.000 & $\mathbf{5 , 3}$ & 10,2 \\
\hline
\end{tabular}

A - Antes das transfusōes.

D - Após transfusões.

* Os casos no 7 e nค 17 não foram transfundidos por não apresentarem anemia. 
MASPES, V. \& TAMIGAKI, M. Anemia ancilostomótica: estudo da fisiopatologia. Rev. Saúde públ., S. Paulo, 15:611-22, 1981.

$\mathrm{Na}$ desnutrição proteico-energética, os sintomas clínicos devem-se à carência alimentar. Esta deficiência protéica afeta $\circ$ crescimento e, conseqüentemente, influi no funcionamento do sistema nervoso, o que prejudica o desenvolvimento psíquico.

$\mathrm{Na}$ anemia ancilostomótica, a carência de ferro conduz à deficiente produção de hemoglobina. Conseqüentemente, o transporte de oxigênio torna-se insuficiente. Desse modo, o organismo não pode sintetizar as proteinas necessárias, em virtude da falta do elemento mais importante no seu metabolismo, o oxigênio. Existe, portanto, uma deficiência no transporte de oxigênio na anemia anc1lostomótica, que segundo Viteri 19 não está presente na anemia do desnutrido protéicc-energético.

Nos casos deste estudo houve detecção clínica de deficiência no transporte de oxigênio, isto é, sintomas de fraqueza geral acompanhadas de cansaço fácil mas recupe. ração rápida. Este fato foi observado principalmente nos doentes mais jovens que conseguiam desenvolver boa atividade física, porém durante curto periodo de tempo.

Do ponto de vista laboratorial, a anemia ancilostomótica apresenta eritrócitos com hipocromia, microcitose e anisocitose acentuadas, e nos casos mais graves há numerosos poiquilocitos. Por outro lado, a "anemia" do desnutrido proteico-energético é normocítica e normocrômica, ou então moderadamente hipocrômica mas quašs sempre normocitica. É notável também as diferenças no grau de anemia. Esta é mais acentuada nos casos de ancilostomose, como foi demonstrada por Marcondes e col. ${ }^{12}$. Nos casos deste estudo, cerca de metade dos pacientes anêmicos apresentaram microcitose, enquanto a hipocromia estava presente em 11 desses casos (Tabela 2). Quinze dos 17 casos estudados apresentaram baixos niveis de hemoglobina (Tabelas 2 e 3 ). Houve, em alguns casos, grande modificação na taxa de hemoglobina, conforme mostram as Tabelas 2 e 3 . Isso porque en muitos casos vários dias decorreram entre o atendimento ambulatorial e a internação:-
Durante esse intervalo de tempo, alguns casos mostraram piora do estado clinico, motivo pelo qual foram transfundidos (casos no 1 , no 8 e n\%9). Apenas em um destes casos a anemia não foi conseqüente à espoliação de sangue pelos vermes mas sim às metrorragias (caso no 16). Estes mesmos 15 casos foram submetidos à transfusão de 1.000 a $2.000 \mathrm{ml}$ de sangue em $48 \mathrm{~h}$ (Tabela 6 ). Houve elevação do teor de hemoglobina a níveis normais ou próximos do normal (Tabela 6) e, do ponto de vista clínico, os doentes transfundidos mostraram acentuada melhora ou mesmo cura dos sintomas. Entretanto, na carência proteico-energética, os resultados das transfusões são bem diversos: geralmente não há melhora do quadro clínico-laboratorial e, por vezes, ao contrário, ocorre agravamento do estado geral, em virtude da repercussão no setor circulatório.

A grande diferença entre a anemia do desnutrido e a do ancilostomótico reside no mecanismo fisiopatológico. $\mathrm{Na}$ anemia ancilostomótica, ocorre espoliação de sangue pelo verme fixado na mucosa duodenal. Os ancilostomídeos mudam freqüentemente $o$ seu ponto de fixação para a sucção de sangue, e isto determina múltiplas lesões na mucosa duodenal. A cicatrização dessas lesões condiciona o gradual desaparecimento das pregas da mucosa ${ }^{17}$. Desse modo, a área de absorção do ferro ingerido torna-se limitada, o que agrava a carência desse metal no organismo. O verme não acarreta alteração no setor proteico do hospedeiro, pois a quantidade de proteína espoliada é muito pequena. Nos casos deste trabalho, apenas um mostrou hipoalbuminemia (caso n? 5) (Tabela 3).

Estudos hemodinâmicos, como a eritrocinese, contribuem para o melhor conhecimento da fisiopatologia da anemia ancilostomótica. Assim, o "turnover" do ferro plasmático e eritrocitário é muito rápido na anemia ancilostomótica 15 . Outrossim, as taxas de ferro plasmático mostram-se muito baixas na anemia ancilostomótica, enquanto nos desnutridos essas taxas apresentam-se 
MASPES, V. \& TAMigAKI, M. Anemia ancilostomótica: estudo da fisiopatologia. Rev. Saúde públ., S. Paulo, 15:611-22, 1981.

dentro dos limites normais, como demonstra Viteri 19

O teor de ferro plasmático mostrou-se baixo em todos os casos, exceto no caso n" 17. Este caso era portador de leve grau de parasitose e de leve espoliação hemorrágica, mas a auto-medicação à base de ferro provocou a moderada elevação do ferro plasmático (Tabela 3). Todos os casos submetidos à eritrocinese mostraram valores de $T_{1 / 2}$ de $50 \mathrm{Fe}$ abaixo do normal, " que indica um "turnover" de ferro plasmático e eritrocitário mais rápido que o normal. Além disso, a incorporação do ferro à hemoglobina foi máxima em 6 casos e quase total nos outros dois casos.

As perdas de sangue intestinal provocadas pela infecção ancilostomótica foram volumosas em alguns casos, como o n? 5 (199 $\mathrm{ml}$ por dia), e geralmente foram proporcionais ao grau de infecção (Tabelas 4 e 5). Deve-se levar em consideração que as condições hemostáticas do individuo podem influir no volume espoliado. Pode-se notar como esses volumes de sangue podem atingir cifras elevadas, em relação à volemia, quando se comparam os casos no 2 e n? 7 .

O caso no 2 é uma criança de $25 \mathrm{~kg}$ de peso corporal que apresentou perda de sangue diária de $23,7 \mathrm{ml}$, e o caso no 7 é de $u \mathrm{~m}$ adulto de $55 \mathrm{~kg}$, cujo volume de sangue perdido foi quase equivalente $(22,0$ $\mathrm{ml}$ por dia) ao do caso no 2 (Tabelas 1 e 4). O caso no 7, que havia sido transfundido antes da internação, e porisso não mostrava anemia (Tabelas 2 e 3 ), manteve-se em estado de equilibrio hematimétrico durante o decorrer do estudo. Nos casos no 16 e $n^{\circ} 17$, a perda hemorrágica foi muito pequena, o que se explica pelo pequeno grau de infecção.

Pode-se notar, na Tabela 4, que, embora a perda de sangue fosse das menores $(22,0$ $\mathrm{ml}$ por dia), a perda de homoglobina foi intermediária $(2,3 \mathrm{~g} / \mathrm{dia})$ no caso no 7 , em comparação com os demais casos. Nos casos no 12 e 15 observa-se que os teores de hemoglobina perdida foram equivalentes, mas o volume de sangue perdido nas fezes foi quase o dobro do 1 ị em relação ao $2^{\circ}$ caso. Por outro lado, a taxa de hemoglobina no sangue deste último caso mostrou-se maior $(6,9 \mathrm{~g} / \mathrm{dl})$ que o dobro da do $1 \fallingdotseq(2,8 \mathrm{~g} / \mathrm{dl})$ (Tabela 3). Isso mostra que a patogenia da infecção ancilostomótica fundamenta-se no conteúdo em hemoglobina e não no volume de sangue sugado do individuo 18

Nota-se também que, para contrabalançar a perda hemorrágica, todos os doentes reabsorveram considerável quantidade do ferro perdido na hemorragia intestinal (Tabela 4). Desse modo, o ferro efetivamente perdido nas fezes foi bem menor que o total contido no volume de sangue perdido (Tabela 4). Apenas o caso no 12 mostrou reabsorção nula do ferro da hemorragia intestinal, por motivos que não se conseguiu determinar.

A reabsorção do ferto pela mucosa intestinal explica a diferença que existe entre as perdas hemorrágicas pela via digestiva e as que ocorrem através de outras vias como a vaginal. A evolução clínica, nesta última eventualidade, é mais rápida, em virtude da impossibilidade de reabsorção do ferro pela mucosa vaginal. É o que ocorreu no caso no 16 , que apresentava metrorragias, embora a discreta infecção verminótica provocasse pequena perda de sangue intestinal (Tabelas 4 e 5). As metrorragias, que não eram constantes nem tão volumosas como as perdas de sangue intestinais dos demais casos, conduziu o doente à carência de ferro mais rapidamente.

Ao final do estudo, todos os casos foram submetidos a adequado tratamento antiverminótico, o que permitiu a manutenção da cura clínica. No entanto, pôde-se observar, em estudo paralelo, que os doentes ancilostomóticos transfundidos, mas não tratados com vermifugos, permanecem longo periodo de tempo sem anemia.

\section{CONCLUSÕES}

O estudo de 17 individuos parasitados com ancilostomideos permitiu chegar às seguintes conclusões: 
MASPES, V. \& TAMIGAKI, M. Anemia ancilostomótica: estudo da fisiopatologia. Rev. Saúde públ., S. Paulo, 15:611-22, 1981 .

1. Infecçōes de moderado a acentuado grau conduziram à anemia em 15 casos. Nos casos restantes, portadores de leve grau de infecção, um deles não mostrou alteração hematológica e o outro apresentou anemia como conseqüência de metrorragias.

2. O padrão proteico da anemia ancilostomótica mostrou-se normal, com exceção de um caso que apresentou hipoalbuminemia.

3. A hipoferremia, ao lado da maior velocidade de renovação do ferro plasmático $\left(\mathrm{T} 1 / 2\right.$ do $\left.{ }^{59} \mathrm{Fe}\right)$ e da elevada incorporaçāo do ferro à hemoglobina, indica que a carência de ferro foi a causa da anemia ancilostomótica.

4. A grosso modo, há relativa correspondência entre o grau de infecção e o volume de sangue perdido.

5. Quanto mais anêmico o individuo parasitado, maior é o volume de sangue perdido nas fezes, pois o verme necessita tão somente da hemoglobina contida nesse volume.

6. O teor de hemoglobina e, portanto, de ferro perdido na hemorragia intestinal, foi muito grande nos casos de moderado a elevado grau de infecção.

7. A reabsorção de considerável porção do ferro da hemorragia intestinal atingiu percentuais variáveis entre $38 \%$ a $68 \%$ nos casos deste estudo. A reabsorção de ferro, nessas condições, constituiu um mecanismo de defesa do organismo contra a rápida progressão da anemia.

8. A transfusão de sangue nos doentes anêmicos produziu melhora clínica $e$ laboratorial imediata.

\section{AGRADECIMENTOS}

Au Prof. Dr. Yaro Ribeiro Gandra, da Faculdade de Saúde Pública da USP, pelos valiosos conselhos e sugestóes.

MASPES, V. \& TAMIGAKI, M. [Ancylostomotic anemia: a contribution to the study of its physiopathology]. Rev. Saúde públ., S. Paulo, 15:611-22, 1981.

ABSTRACT: Seventeen ancylostomotic patients was studied and several hematological parameters: hemoglobin level, serum iron level and transferrin, erythrocyte count, hematocrit, mean corpuscular volume (VCM) and mean corpuscular hemoglobin (HCM) was established. This study also included the determination of several erythrokinetic data such as plasma iron turnover and red cell iron turnover. Radioisothopic assays also permitted the estimation of blood volume and hemoglobin lost through feces, as well as the amount of iron absorbed from this hemoglobin. The authors also established the intensity of the patient's infection by egg and worm counts. The patients presented no evident nutritional abnormality. Iron deficiency was the common factor found among those who had anemia, and it constitutes the physiopathologic basis of ancylostomotic anemia. The worms fixed on the intestinal epithelium suck the host's blood and this long-term blood spoliation produces anemia. The volume of blood lost is generally proportional to the degree of infection, but the fall in the patient's hemoglobin level was found to be independent of the spoliated blood volume. The great amount of iron which is absorved from the hemoglobin shed into the feces contributes to the later establishment of anemia as compared to that of other hemorrhages, as for instance, vaginal hemorrhages. The anemic patients were submitted to blood transfusions and thereafter presented an immediate although temporary clinical and laboratorial improvement. A steady clinical improvement, however, was established only after adequate worm therapy.

UNITERMS: Ancylostomiasis. Anemia. Hematology. 
MASPES, V. \& TAMIGAKI, M. Anemia ancilostomótica: estudo da físiopatologia. Rev. Saúde públ., S. Paulo, $15: 611-22,1981$.

\section{REFERENCIAS BIBLIOGRAFICAS}

1. AMATO NETO, V.: CAMPOS, R. \& FERREIRA, C.S. Diagnóstico das parasitoses intestinais pelo exame de fezes. 3: ed. São Paulo, Atheneu Edit., 1969

2. CLARK, C.H.; KLING, J.M.; WOODLEY, C.H. \& SHARP, N. A quantitative measurements of the blood loss calsed by Ancylostomyasis in dogs. Amer. $J$ vet. Med., 22:370-3, 1961.

3. CRUZ, W.O. Hipótese sobre a patogeni: da anemla ancilostomotica. Papel preponderante da deficiência de ferro no organismo. Brasil méd., 46:593-7, 1932

4. CRUZ, W.O. Patogenia da anemia na ancilostomose. I - Portadores de parasitos. Relação entre a atividade do helminto e a deficiência de ferro na gênese da doença. Mem. Inst. Oswaldo Cruz, 28:391-439, 1934.

5. CRUZ, W.O. Patogenia da anemia na ancilostomose. II - Causas determinantes dos fenômenos regenerativos $\epsilon$ degenerativos nessa anemia e contribuições para elucidar o seu mecanismo intimo. Mem. Inst. Oswaldo Cruz, $29: 263-427,1934$.

6. CRUZ, W.O. Patogenia da anemia na ancilostomose. III - Modificações hemáticas e orgánicas provocadas pela simples eliminação do ancilóstomo e do necator em individuos fortemente anemiados. Mem. Inst. Oswaldo Cruz, 29:487-540, 1934.

7. CRUZ, W.O. \& PIMENTA DE MELLO, R. Prophilaxis of hookworm anaemia deficiency disease. Blood, 3:457-64, 1948.

8. EBAUGH, P.G.; CLEMENS, T.; RODMAN, G. \& PETERSON, E.R. Quantitative measurements of gastrointestinal blood loss. Amer. J. Med., $25: 169-81,1958$.

9. FERREIRA, C.S. Contagem de ovos de helmintos nas fezes: algumas modificações. Rev. paul. Med., 68:240, 1966.

10. FERREIRA, C.S. \& REIS, A.A. Contagem de ovos de helmintos nas fezes: comparação entre os métodos de Stoll-Hansheer e da câmara de contagem segundo Santos Ferreira. Rev. paul. Med., 74:331-2, 1969.
11. GORNALL, A.G.; BARDAWILL, C.J. \& DAVID, M.M. Determination of serum proteins by means of the biuret reaction. J. biol. Chem., $177: 751-66,1949$.

12. MARCONDES, E.; COELHO, H.S.; NEVES Fo, F.F.; SILVA, J.A.; RIBEIRO, M.B.; FIORE, F.F. \& ELIAS, L.E. Desnutrição na infância: terminologia de algumas considerações clínicas baseadas na revisão de 230 observaçóes de "distrofia carencial" e quatro observações de "atrofia". Rev. Hosp. Clin., 18:17-9, 1963.

13. MASPES, V.; FERREIRA, C.S. \& TAM1GAKI, M. Modificações produzidas por transfusões de sangue na postlira de ancilostomídeos. Rev. Inst. Med. trop. S. Paulo, 20:315-67, 1978.

14. MASPES, V.; JAMRA, M.; CILlo, D.M.; PIERONI, R.R.; GOMEZ, Z. J. \& MORAIS REGO, $S$. Contribución al estudio del metabolismo del hierro en hemopatias diversas mediante el empleo de los isotopos radiactivos $59 \mathrm{Fe}$ y $51 \mathrm{Cr}$. Sangre, 4:351-412, 1959.

15. MASPES, V. \& TAMIGAKI, M. Anemia ancilostomótica: avaliação dos componentes hemolítico e hemorrágico. Importância desses fatores na determinação do grau de anemia. Rev. Hosp. Clin., 35: 60-5, 1980.

16. MASPES, V. \& TAMIGAKI, M. Padronização de métodos para dosagem do ferro sérico e da siderofilina no soro. Rev. Hosp. Clin., 30:126-31, 1975.

17. ROCHE, M. \& LAYRISSE, M. The nature and causes of hookworm anaemia. Amer. J. trop. Med. Hyg., 15:1031-102, 1966.

18. ROCHE, M. \& MARTINEZ TORRES, C. A method for "in vitro" study of hookworm activity. Exp. Parasit., 9:250-6, 1960.

19. VITERI, F.E.; ALVARADO, J.; LUTHRIN. GER, D.G. \& WOOD, R.P. Hematological changes in protein caloric malnutrition. Vitam. \& Horm., 26:573-616, 1968 .

Recebido para publicação em 30/04/1981 Aprovado para publicaço em 17/11/1981 